\title{
Behavioral Study on the Use of Cosmetics and Skin-Care Products among Female University Students in their 20s
}

\author{
Eun Jung Doh ${ }^{1}$, Hae Jung Hwang ${ }^{2 \star}$ \\ ${ }^{1}$ Ye-rang Art School, Soul, Korea \\ ${ }^{2}$ e-Nuri Lifelong Education Center, Seoul, Korea
}

\author{
"Corresponding author: Hae Jung Hwang, \\ e-Nuri Lifelong Education Center, 366, \\ Yangcheon-ro, Gangseo-gu, Seoul 07573, \\ Korea \\ Tel.: +82 236620480 \\ Fax: +82 236620494 \\ Email: nerohwang@naver.com
}

Received August 24, 2020

Revised November 05, 2020

Accepted November 30, 2020

Published December 30, 2020

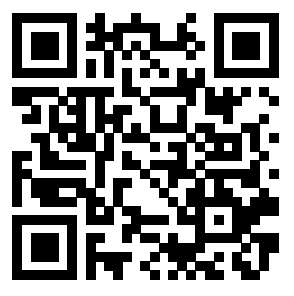

\begin{abstract}
Purpose: To correct misperceptions about makeup use among younger age groups and to support opportunities for education, this study analyzed makeup use and skin-care behavior among young people in their 20s. Methods: A survey was conducted among 130 female students living in Seoul/Gyeonggi Province concerning general characteristics, skin knowledge, and behavior. Frequency analysis was applied to the survey data using SPSS WIN 12.0 software for statistical processing. Result: Most of the surveyed females in their 20s used base (foundation makeup) to cover defects, and there was wide recognition that warm water should be used when washing the face. Use of a professional facial cleanser improved facial skin appearance. Because of the financial burden, however, most participants usually used self-administered skin-care. Facial massage and packs were widely used self-care treatments, and most respondents believed these treatments to be effective. The most common causes of side effects from cosmetic products involved the cleaning of cosmetic tools $(p=0.022)$ and skin-care methods ( $p=0.005)$. Conclusion: This study provides guidelines for young cosmetic product users to overcome misinformation, incorrect usage and bad habits related to cosmetic products. This paper also provides information to a variety of cosmetic products, and by applying information, students could experience lower incidence of skin trouble when using cosmetic products.
\end{abstract}

Keywords: Base (foundation), Washing face, Professional cleanser, Message, Pack

\section{Introduction}

메이크업은 얼굴과 신체의 결점을 수정, 보완하여 아름답게 하는 인간의 미적 본능에 대한 원초적 표현이고 화장도구를 사용하여 신 체를 보호하고 장식하는 행위로, 외적, 내적 자기 감각을 표현하는 창조의 수단이다(Jang \& O, 2008). 메이크업은 색채를 이용하여 사 회적 신분과 개성을 표현하고, 연령 및 외모를 변화시키고 싶은 직 간접적인 심리적 이미지 메이킹(imagemaking) 수단으로 폭넓게 활 용되고 있다(Hong \& Kim, 2015). 산업 환경이 변화하면서 사람들 이 메이크업에 대한 인식과 기법 등에 다양한 변화가 이루어지고 있 는데 오늘날 현대인은 좋은 이미지와 깨끗한 외모를 선호하고 밝고 자연스러운 아름다움을 선호하는 경향이 대두되고 있다(Lim et al., 2010). 메이크업은 미적으로 외모를 개선하나 색조화장품 등이 모 공을 막고 땀 피지 각질 노폐물 등으로 피부 노화의 원인이 되기도
하므로 건강하고 깨끗한 피부를 위해서 세안은 필수 조건이다(Kim, 2007). 화장의 시작과 끝은 세안이라는 말에서도 알 수 있듯이 메이 크업에 있어서 지우는 것은 아주 중요하다(Ha et al., 2002). 깨끗하 고 밝은 톤의 피부는 아름다움의 중요한 판단 기준이 되어 미인 선 별기준에서 중요한 역할을 한다(Vie et al., 2000). 그래서, 피부 관 리 단계에 효과적인 영향을 주는 피부 개선을 위한 화장품 선호도가 높아지고 수요도 증가하고 있다. 특히, 간편하고 경제적으로 자신을 꾸밀 수 있는 마스크팩 제품의 시장 점유율이 높아지고 있다. 마스 크팩은 다양한 영양성분이 피부 흡수되어 손쉽게 피부를 관리할 수 있고 저렴한 가격 대비 보습, 미백, 노화방지, 노폐물 제거 등의 우 수한 효과를 제공한다. 이러한 장점으로 최근 남녀노소를 불문하고 인기를 끌고 있다(Kwon, 2019). 피부 탄력부여, 피부재생, 미백 등 모델링 마스크는 집중 케어 영양 화장품으로 인식되어 홈케어 제품 
으로 많이 사용되고 있다는 선행 연구(Choi \& Kim, 2016)를 통해 서도 효과가 나타났다. 화장을 시작하는 연령층이 낮아지고 있는 현 시점에서 피부 건강에 대한 인식과 관리에 관한 연구(Jeong et al., 2011), 여대생들의 메이크업 화장품 구매 행동 및 사용실태에 관한 연구(Kim \& Kim, 2013)등과 같은 20대 대상의 화장행위, 미용 트 랜드 수용 등에 관한 선행연구와 더불어 청년층의 화장품 사용 현 황 조사, 건강한 피부 관리를 위한 행동 방안을 제시하는 연구가 이 어져야 하고 건강하고 안전한 사회에서 정확한 정보 제공이 이루어 져야 할 것이다. 이에 본 연구는 여대생들의 화장품 사용 및 피부 관 리를 위한 실태를 파악하여 화장에 대한 잘못된 지식 습득, 습관으 로 피부 관리에 범하게 되는 오류를 바로 잡아 화장품 사용의 정확 한 행동 방안을 제시하고자 한다. 또한, 낮아지는 화장 연령층에 대 한 교육 필요성의 계기가 되고 건강한 피부 관리를 위한 후속 연구 로 이어지는데 도움이 되고자 한다.

\section{Methods}

\section{1. 연구 대상}

20 대 여성들의 피부관리를 위한 화장품 사용실태를 조사하여 점 점 낮아지는 화장 연령층의 피부 관리 실태를 파악하는 계기가 되고 잘못된 화장습관에 대한 교육 확대의 기회를 만들고자 서울, 경기 지역 대학교(S, H 대학교) 20 대 여대생 130 명 대상으로 설문 조사 하였다.

\section{2. 연구 도구}

본 연구의 설문지 구성은 색조화장품에 관한 평가, 화장품 부작용 에 관한 평가, 세안에 관한 평가, 세안제에 관한 평가, 피부관리 및
피부관리실 이용에 관한 평가 등으로 구분하였으며 총 25 문항으로 구성된 자기 기입식 설문지 방식을 채택하였다. 설문지 구성 내용은 Table 1에 제시하였다.

\section{3. 자료분석}

조사대상자의 일반적인 특성, 화장 관련 특성, 피부관리 특성에 대한 기초통계량 분석을 위해 빈도 분석(frequency analysis)하였 고 화장품 부작용 경험에 대한 인자의 독립성 검증은 카이제곱 검정 통계량으로 분석하였다. 해 통계 처리는 SPSS WIN 12.0 프로그램 (IBM, USA)을 사용하여 분석하였다.

\section{Results}

\section{1. 연구대상자의 일반적 특성}

연구 대상자의 일반적 특성에 대한 빈도 분석 결과, 연구 목적의 특성상 성별이 모두 여성 이었고, 연령은 20-22세 이하가 89명, 23 세 이상-25세 이하 19 명으로 22 세 이하의 비중이 높았다. 학교 분 포는 서울 및 경기 지역에 위치한 2 년제 대학교이고 화장품 및 피부 관리에 대한 일반적 사항을 설문지로 작성하여 분석하였다. 연구 대 상자의 일반적 특성은 Table 2에 제시하였다

\section{2. 색조화장품 사용 실태조사}

색조화장품 사용실태의 설문결과, 메이크업 시 가장 많이 사용하 는 색조화장품은 베이스(파운데이션) $57.4 \%$, 마스카라 $14.8 \%$, 새도 우 및 립 $11.1 \%$ 로 베이스(파운데이션) 색조화장품을 가장 많이 사용 하는 것으로 나타났다. 색조 메이크업 시 가장 많이 신경 쓰는 점은 결점 커버 $56.2 \%$, 베이스 $21.9 \%$, 립 $9.5 \%$ 로 색조 화장 시 결점 커

Table 1. Question configuration

\begin{tabular}{|c|c|c|c|}
\hline Part & Question content & Question number & Source \\
\hline I & Evaluation of face washing & Coating & $\begin{array}{l}\text { Vie et al. (2000) } \\
\text { Kim (2007) } \\
\text { Song et al. (2010) }\end{array}$ \\
\hline II & Evaluation of skin-care and visits to skin-care shops & Coating & Shin et al. (2009) \\
\hline III & Evaluation of side effects from cosmetic products & Mixing & Lee et al. (2004) \\
\hline IV & Evaluation of pigmented cosmetic products & Mixing & Lee et al. (2009) \\
\hline
\end{tabular}

Table 2. General characteristics

\begin{tabular}{|c|c|c|c|}
\hline Variables & & $\mathrm{N}$ & Percent (\%) \\
\hline \multirow{2}{*}{ Gender } & Male & 0 & 0 \\
\hline & Female & 108 & 100.0 \\
\hline \multirow{2}{*}{ Age } & Greater than 20 and less than 22 years old & 89 & 82.4 \\
\hline & Greater than 23 and less than 25 years old & 19 & 17.6 \\
\hline \multirow{2}{*}{ School location } & Seoul & 69 & 63.9 \\
\hline & Kyeonggi-do & 39 & 36.1 \\
\hline
\end{tabular}


버를 가장 많이 신경 쓰는 것으로 나타났다.

메이크업 후 수정 보완 횟수(하루기준)는 1 회 $28.7 \%$, 수시로 $26.9 \%, 2$ 회 $21.3 \%$ 로 하루에 수정 보완을 하는 횟수는 1 회가 가장 많았다.

메이크업 수정 보완을 많이 하는 내용은 베이스(파우더) $34.7 \%$, 립 $30.6 \%$, 유분기만 제거 $26.5 \%$ 로 메이크업 수정 보완 시 베이스 (파우더)를 가장 많이 신경 쓰는 것으로 나타났다. 색조 메이크업에 서 가장 신경 쓰는 것은 아이 메이크업 $49.5 \%$, 결점 커버 $25.2 \%$ 로 아이 메이크업에 가장 많이 신경 쓰는 것을 알 수 있었다. 메이크업 도구인 퍼프나 브러쉬 등의 세척에 대한 조사에서 더럽다고 느껴질 때 $68.2 \%$, 전혀 하지 않는다 $13.1 \%$, 새 제품 교환 시 $11.2 \%$ 로 메이 크업 도구에 대한 세척은 더럽다고 느껴지는 개인의 감정에 따라 시 기가 결정되는 것으로 나타났다. 색조화장품 사용에 대한 일반적 사 항은 Table 3에 제시하였다.

\section{3. 화장품 부작용 경험 여부}

화장품 관련 설문 분석 결과, 화장품 부작용 경험자 $43.0 \%$, 경험
이 없는자 $57.0 \%$ 로 화장품 부작용을 경험하지 않은 경우가 약간 더 높게 나타났다.

화장품 부작용을 경험했을 때 조치방법은 전문 피부과 치료 $31.1 \%$, 방치 $28.9 \%$, 기타 $22.2 \%$ 로 전문 피부과 진료를 받는 비 중이 높았다. 마사지와 팩을 사용한 후 부작용 경험 여부는 있다 $27.8 \%$, 없다 $72.2 \%$ 로 마사지와 팩 사용의 부작용은 낮은 것으로 나 타났다.

클렌징 후 피부 트러블 현상은 건조 $55.7 \%$, 전혀 없다 $32.1 \%$, 각 질 $7.5 \%$ 로 클렌징 후 건조증상의 피부 트러블이 많은 것으로 나타 났으며 대처방안으로는 수분크림팩 $62.0 \%$, 방치 $23.9 \%$ 로 주로 수 분크림팩으로 피부 트러블을 대처하는 것으로 나타났다. 화장품 관 련 일반적 사항은 Table 4에 제시하였다.

\section{4. 피부관리를 위한 세안제의 일반적 특성}

피부관리를 위한 세안에 대한 일반적 사항 분석 결과, 폼클렌징 사용 $60.2 \%$, 이중 세안 $32.4 \%$, 비누 세안 $6.5 \%$ 로 세안 시 폼클렌징 사용 비중이 높았다. 또한 화장은 지우는 것(클렌징)이 매우 중요하

Table 3. Makeup use

\begin{tabular}{|c|c|c|c|}
\hline Question & & Frequency $(\mathrm{N})$ & Percent (\%) \\
\hline \multirow{5}{*}{ What makeup is most commonly used? } & None & 6 & 5.6 \\
\hline & Mascara & 16 & 14.8 \\
\hline & Eye-shadow & 12 & 11.1 \\
\hline & Lipstick & 12 & 11.1 \\
\hline & Base (foundation) & 62 & 57.4 \\
\hline \multirow{5}{*}{$\begin{array}{l}\text { How many touchups are made after } \\
\text { makeup application (daily) }\end{array}$} & None & 14 & 13.0 \\
\hline & One & 31 & 28.7 \\
\hline & Two & 23 & 21.3 \\
\hline & Three & 11 & 10.2 \\
\hline & Frequently & 29 & 26.9 \\
\hline \multirow{5}{*}{$\begin{array}{l}\text { What are the most common targets for } \\
\text { correction? }\end{array}$} & None & 7 & 7.1 \\
\hline & Lipstick & 30 & 30.6 \\
\hline & Rouge/blush & 1 & 1.0 \\
\hline & Oil removal & 26 & 26.5 \\
\hline & Base (powder) & 34 & 34.7 \\
\hline \multirow{5}{*}{$\begin{array}{l}\text { What are the areas of most concern after } \\
\text { application of pigmented makeup? }\end{array}$} & None & 9 & 8.4 \\
\hline & Covering defects & 27 & 25.2 \\
\hline & Eye makeup & 53 & 49.5 \\
\hline & Lipstick & 8 & 7.5 \\
\hline & Base & 10 & 9.3 \\
\hline \multirow{5}{*}{ How often are makeup tools cleaned? } & None & 14 & 13.1 \\
\hline & When they feel dirty & 73 & 68.2 \\
\hline & $\begin{array}{l}\text { When switching to new makeup } \\
\text { products }\end{array}$ & 12 & 11.2 \\
\hline & Once a month & 7 & 6.5 \\
\hline & Twice a month & 1 & 0.9 \\
\hline
\end{tabular}


고 미지근한 물을 사용해서 세안하는 것이 효과적이다 라고 인식하였 다. 피부 고민은 모공 관리 $41.7 \%$, 유,수분 균형 $20.4 \%$, 세안 후 청결 감 $19.4 \%$, 색조 착색 여부 $12.0 \%$ 로 모공 관리에 대한 고민이 가장 높 았다. 색조 화장 후 세안 방법은 전용 폼클렌징 $42.3 \%$, 이중 세안(유 성+수성) $31.7 \%$, 전용 리무버 사용 $20.2 \%$ 로 전용 폼클렌징을 사용하 여 세안하는 비중이 높았다. 전문 세안제(각질 제거, 모공 클렌저)를 사용해 본 경험에 대한 설문결과, 경험 있다 $89.8 \%$, 경험 없다 $2 \%$ 로 전문세안제(각질 제거, 모공 클렌저)를 사용 비중이 높았고, 전문세안 제(각질 제거, 모공 클렌저)사용 후 피부가 예전보다 좋아졌는지에 대 한 설문결과, 피부가 전보다 좋아졌다는 의견이 높았다. 피부관리를 위한 세안제의 일반적 특성은 Table 5 와 같다.

\section{5. 피부관리를 위한 피부관리실의 이용형태}

전문 피부관리를 받아본 적이 있거나 본인이 셀프 피부관리를 해본 경험이 있는지에 대한 설문 조사 결과, 둘 다 있다 $42.5 \%$ 로 높게 나타 났고, 전문 관리를 받아본 적이 있다 $27.4 \%$, 둘 다 없다 $19.8 \%$ 로 전문 피부관리를 받아본 적이 있거나 셀프 피부관리 한 적이 있다는 응답자 가 많았다. 피부관리를 받아본 적이 있는 경우, 피부관리를 받는 곳은 전문 피부관리실 $53.1 \%$ 로 높았고, 피부과 내 피부관리실 $22.4 \%$, 홈케
어가 $18.4 \%$ 로 전문 피부관리실에서 피부관리를 받는 것으로 나타났 다. 셀프 피부관리 시 팩과 마사지의 효과에 대한 설문조사 결과, 만족 한다는 긍정 응답 (만족한다+매우 만족한다) $53.7 \%$, 보통 $42.6 \%$, 불 만족 $3.7 \%$ 로 팩과 마사지를 경험한 후의 만족도가 높은 것으로 나타 났다. 피부관리를 전문적으로 받고 싶은 이유는 결점 개선 $45.3 \%$, 탄 력 $26.4 \%$, 수분 개선 $17.0 \%$ 순으로 나타나 결점 개선을 위해 피부관 리를 전문적으로 받고 싶어 하는 응답자가 많은 것으로 나타났다. 피 부관리를 했을 때와 하지 않았을 때 차이를 느끼는지에 대한 조사 결 과, 그렇다는 긍정 응답(그렇다+매우 그렇다) $69.8 \%$, 보통 $30.2 \%$ 로 피부관리를 했을 때와 하지 않았을 때 차이가 있는 것을 알 수 있었다. 피부관리 받지 않는 이유는 경제적 부담 $61.0 \%$, 필요성 없다 $19.5 \%$, 기타 $17.1 \%$ 순으로 피부관리를 받지 않는 주된 요인은 경제적 부담으 로 나타났다. 피부관리 및 피부관리실 이용형태는 Table 6 과 같다.

\section{6. 독립성 검증 화장품 부작용 영향 요인}

화장품 부작용 경험에 영향을 주는 요인을 찾기 위해서 Table 7와 같이 독립성 검증을 하였고 양측 검정 $95 \%$ 신뢰구간 범위에서 채택하 였다. 분석결과, 화장품 부작용 경험에 영향을 주는 인자로 화장품 도 구의 세척 여부( $p$-value 0.022), 피부관리 여부( $p$-value 0.005) 인 것

\section{Table 4. Cosmetics-related questionnaire}

\begin{tabular}{|c|c|c|c|}
\hline Questions & & Frequency $(\mathrm{N})$ & Percent (\%) \\
\hline \multirow{2}{*}{ Experienced cosmetics-related side effects } & None & 61 & 57.0 \\
\hline & Experienced & 46 & 43.0 \\
\hline \multirow{5}{*}{$\begin{array}{l}\text { Treatment for cosmetics-related side } \\
\text { effects }\end{array}$} & Dermatological treatment & 14 & 31.1 \\
\hline & Pharmacy & 4 & 8.9 \\
\hline & Skin-care shop & 4 & 8.9 \\
\hline & Neglect & 13 & 28.9 \\
\hline & Other & 10 & 22.2 \\
\hline \multirow{2}{*}{$\begin{array}{l}\text { Experienced side effects after using } \\
\text { massages or packs }\end{array}$} & None & 78 & 72.2 \\
\hline & Experienced & 30 & 27.8 \\
\hline \multirow{5}{*}{$\begin{array}{l}\text { Symptoms of side effects from massages } \\
\text { or packs }\end{array}$} & Itchiness & 17 & 58.6 \\
\hline & Edema & 1 & 3.4 \\
\hline & Red spots & 1 & 3.4 \\
\hline & Dryness & 1 & 3.4 \\
\hline & Acne & 9 & 31.0 \\
\hline \multirow{5}{*}{ Skin trouble after cleansing } & None & 34 & 32.1 \\
\hline & Dryness & 59 & 55.7 \\
\hline & Dead skin & 8 & 7.5 \\
\hline & Itchiness & 2 & 1.9 \\
\hline & Red spots & 3 & 2.8 \\
\hline \multirow{5}{*}{ Treatment for skin trouble after cleansing } & Neglect & 17 & 23.9 \\
\hline & Cold pack & 7 & 9.9 \\
\hline & Hot pack & 1 & 1.4 \\
\hline & Moisturizing cream pack & 44 & 62.0 \\
\hline & Dietary regime & 2 & 2.8 \\
\hline
\end{tabular}


으로 나타났다. 전문 세안제 사용 여부( $p$-value 0.136), 전문 세안제 의 종류(p-value 0.100), 색조화장 사용 여부( $p$-value 0.186)는 화장 품 부작용 경험에 영향을 미치지 않는 것으로 나타났다. 화장품 부작 용 경험에 따른 개인 특성, 화장품 및 피부 관리 특성의 차이 분석결과 는 통계적으로 유의하였다.

\section{Discussion}

본 연구 결과, 20 대 여성들은 결점 커버를 위해서 색조 화장품 중 베이스(파운데이션)을 가장 많이 사용하였고 세안 시 미지근한 물을 사용해야 한다는 인식이 높았다. 이 결과는 여대생의 색조 화장품 선 택 선호도는 비비 크림과 파운데이션이 높았다는 선행 연구(Park, 2013)와 일치하였고 세안 시 물 온도는 미지근한 물로 하는 여성이 가 장 많았다는 선행연구(Baek \& Kim, 2014)결과와 일치하였다. 또한, 피부 관리를 위해서 전문세안제를 사용하고 이로 인하여 피부가 이전
보다 좋아졌다는 인식이 높았다. 이 결과는 피부관리를 효과적으로 하 기 위해서는 올바른 세안습관과 피부유형에 맞는 효과적인 세안화장 품을 선택해야 한다(Lim et al., 2010). 는 선행 연구결과와 상관성이 있었다. 효과적인 피부 관리 방법으로는 연령 및 직업 특성상 경제적 부담을 이유로 스스로 피부관리를 하는 여대생들이 많았으며 마사지 와 팩을 사용한 후 피부 변화에 높은 만족을 표시했고 효능과 효과를 신뢰하는 것으로 나타났다. 이 결과는 여대생들이 비용 문제로 전문 피부관리실에서 관리를 받지 못하고(Kim, 2017), 집에서 스스로 피부 관리하는 여성이 하지 않은 여성보다 수분 상태가 양호하고 스스로 관 리하지 않는 여성은 수분 상태가 낮은 것으로 나타났다는 선행연구 결 과(Hong \& Kim, 2007)와 상관성이 있었다. 화장품 부작용에 대해서 는 경험하지 않은 경우가 더 많았지만 부작용 발생 시, 전문 피부과 진 료를 통해 치료하는 비중이 높았다. 클렌징 후 피부 건조 현상과 피부 마사지와 팩의 부작용으로 가려움증이 가장 많았다. 이 결과는 여대생 들의 뾰루지 및 여드름 형태의 화장품 부작용을 경험하였다는 선행연 구 결과(Kim, 2019)와 차이가 있었고 화장품 번갈아 사용 시 스킨, 로

Table 5. General questions about skin-care and facial washing

\begin{tabular}{|c|c|c|c|}
\hline Variables & & Frequency $(\mathrm{N})$ & Percent (\%) \\
\hline \multirow{4}{*}{ Method of cleansing } & Washing with soap & 7 & 6.5 \\
\hline & Washing with water & 1 & .9 \\
\hline & Washing with foam cleanser & 65 & 60.2 \\
\hline & Double cleansing & 35 & 32.4 \\
\hline \multirow{5}{*}{ Skin-related worries when washing face } & None & 7 & 6.5 \\
\hline & Balance between oil and moisture & 22 & 20.4 \\
\hline & Taking care of pores & 45 & 41.7 \\
\hline & Feeling fresh after cleansing & 21 & 19.4 \\
\hline & Left over makeup stains & 13 & 12.0 \\
\hline \multirow{5}{*}{ Cleansing method after pigmented makeup } & None & 2 & 1.9 \\
\hline & Double cleansing (oil+ moisturizer) & 33 & 31.7 \\
\hline & Washes with soap & 4 & 3.8 \\
\hline & Uses special foam cleanser & 44 & 42.3 \\
\hline & Uses special makeup remover & 21 & 20.2 \\
\hline \multirow{2}{*}{ Experience using special face cleanser } & No & 11 & 10.2 \\
\hline & Yes & 97 & 89.8 \\
\hline \multirow{5}{*}{$\begin{array}{l}\text { Differences after using special face } \\
\text { cleansers }\end{array}$} & No improvements & 11 & 11.5 \\
\hline & Uses it habitually/already used & 17 & 17.7 \\
\hline & Mild improvement & 53 & 55.2 \\
\hline & Improvement & 14 & 14.6 \\
\hline & Significant improvement & 1 & 1.0 \\
\hline \multirow{5}{*}{$\begin{array}{l}\text { Reasons for not using special face } \\
\text { cleansers }\end{array}$} & Does not feel the need to use & 3 & 30.0 \\
\hline & $\begin{array}{l}\text { Feels like using special face cleanser } \\
\text { will make the skin worse }\end{array}$ & 1 & 10.0 \\
\hline & Never used it before & 4 & 40.0 \\
\hline & It is expensive & 1 & 10.0 \\
\hline & Does not use pigmented makeup & 1 & 10.0 \\
\hline
\end{tabular}


션의 피부 부작용이 높고 부작용 증상으로 뾰루지, 붉어짐, 가려움증 이 많았다(Lee et al., 2004)는 선행연구와 상관성이 있었다. 화장품 부작용 경험에 영향을 주는 인자로 화장품 도구의 세척 여부( $p$-value $0.022)$, 피부관리 여부( $p$-value 0.005) 인 것으로 나타났다. 이는 화
장품 부작용 경험자들을 중심으로 고가 브랜드와 천연화장품에 대한 수요가 높아 지고 있기에 제품의 품질과 유해물질 여부를 정확 하고 올바르게 표기할 필요가 있다는 선행 연구 결과(Kim, 2019)와 상관성 이 있었다.

Table 6. Experience with skin-care and skin-care shops

\begin{tabular}{|c|c|c|c|}
\hline Variables & & Frequency $(\mathrm{N})$ & Percent (\%) \\
\hline \multirow{4}{*}{$\begin{array}{l}\text { Experience in getting specialist skin-care } \\
\text { vs. self-care }\end{array}$} & Received neither & 21 & 19.8 \\
\hline & Received specialist care & 29 & 27.4 \\
\hline & Received both & 45 & 42.5 \\
\hline & Received self skin-care only & 11 & 10.4 \\
\hline \multirow{5}{*}{ Places to get skin-care products } & Never purchased & 2 & 4.1 \\
\hline & From a dermatologist & 11 & 22.4 \\
\hline & From a Chinese medical hospital & 1 & 2.0 \\
\hline & Homecare & 9 & 18.4 \\
\hline & From a specialist skin-care shop & 26 & 53.1 \\
\hline \multirow{4}{*}{$\begin{array}{l}\text { Effects of self-applied facial mask and } \\
\text { massage }\end{array}$} & Not satisfied & 2 & 3.7 \\
\hline & Just okay & 23 & 42.6 \\
\hline & Satisfied & 26 & 48.1 \\
\hline & Very satisfied & 3 & 5.6 \\
\hline \multirow{5}{*}{ Reasons to get skin-care from specialists } & Improves elasticity & 14 & 26.4 \\
\hline & Improves moisturization & 9 & 17.0 \\
\hline & Improves defects & 24 & 45.3 \\
\hline & Improves wrinkles & 1 & 1.9 \\
\hline & Relaxing & 5 & 9.4 \\
\hline \multirow{3}{*}{ Difference pre-and post-skin care } & Agree & 22 & 41.5 \\
\hline & Strongly agree & 15 & 28.3 \\
\hline & Neutral & 16 & 30.2 \\
\hline \multirow{4}{*}{ Reasons not to get skin-care } & Does not feel a need & 8 & 19.5 \\
\hline & Lack of time & 1 & 2.4 \\
\hline & Expensive & 25 & 61.0 \\
\hline & Other & 7 & 17.1 \\
\hline
\end{tabular}

Table 7. Independence test

\begin{tabular}{|c|c|c|c|c|c|}
\hline \multirow[t]{2}{*}{ Variables } & & \multicolumn{2}{|c|}{$\begin{array}{c}\text { Experienced skin trouble from product } \\
\text { use }\end{array}$} & \multirow[t]{2}{*}{ Test statistics } & \multirow[t]{2}{*}{$p$-value } \\
\hline & & Yes (Frequency) & No (Frequency) & & \\
\hline \multirow{2}{*}{ Tools for removing makeup } & Used & 36 & 57 & \multirow{2}{*}{$x^{2}=5.248^{* *}$} & \multirow{2}{*}{0.022} \\
\hline & Did not use & 10 & 4 & & \\
\hline \multirow{2}{*}{ Use of professional cleansers } & Used & 39 & 58 & \multirow{2}{*}{$x^{2}=2.218^{*}$} & \multirow{2}{*}{0.136} \\
\hline & Did not use & 7 & 4 & & \\
\hline \multirow{2}{*}{ Type of professional cleanser } & Soap & 5 & 2 & \multirow{2}{*}{$x^{2}=2.704^{*}$} & \multirow{2}{*}{0.100} \\
\hline & Foam cleanser & 40 & 60 & & \\
\hline \multirow{2}{*}{ Applied makeup } & Did & 45 & 57 & \multirow{2}{*}{$x^{2}=1.746^{*}$} & \multirow{2}{*}{0.186} \\
\hline & Did not & 1 & 5 & & \\
\hline \multirow{2}{*}{ Doing skin-care } & Did & 45 & 40 & \multirow{2}{*}{$x^{2}=8.027^{* *}$} & \multirow{2}{*}{0.005} \\
\hline & Did not & 4 & 17 & & \\
\hline
\end{tabular}

${ }^{*} p<0.05 ;{ }^{* *} p<0.001$. 


\section{Conclusion}

본 연구 결과, 20 대 여대생들이 가장 많이 사용하는 색조화장품 은 화운데이션(베이스) 이었고 피부관리를 위해서 색조화장 후 전문 세안제를 사용하고 마사지와 팩을 이용한 셀프 관리를 많이 하는 것 으로 나타났다. 또한, 화장품 부작용 경험에 영향을 미치는 요인은 화장 도구 세척 및 피부관리 여부인 것으로 나타났다. 화장 연령층 이 점점 낮아지고 있는 시점에서 본 연구가 화장품에 대한 정보 오 류와 잘못된 화장품 사용 및 생활 습관으로 피부 부작용을 경험하지 않도록 하는 기초 자료로 활용되고, 화장품에 대한 정보 공개의 다 양성과 교육의 기회가 제공되어지는 계기가 되길 바란다. 연구의 한 계성으로는 특정 지역의 20 대 여대생을 대상으로 한 연구 결과이기 에 젊은 연령층의 일반화된 결과로 인식하기에 무리가 있고 한정적 제한이 따른다. 본 연구를 통하여 청소년들의 화장 실태에 관한 후 속연구가 다양하게 확대되어 이루어진다면 건강한 화장 문화가 형

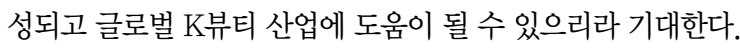

This work is part of the Eun-jung Doh's M.S. thesis at the University of Chung-Ang University Graduate School of Medicine and Food, Seoul, Korea.

\section{Author's contribution}

EJD and HJH contributed equally to this work. EJD collected data from females who are in their 20s and provided fundamental data sets. HJH used the data to wrtie analysis and finish the paper.

\section{Author details}

Eun Jung Do (Principal), Ye-rang art school, 42, Hakdong-ro 38-gil, Gangnam-gu, Seoul 06106, Korea; Hae Jung Hwang (Professor), e-Nuri Lifelong Education Center, 366, Yangcheon-ro, Gangseo-gu, Seoul 07573, Korea.

\section{References}

Baek JH, Kim JD. A study on women's cleansing awareness and use of cleansing products. Korean Society of Cosmetics and Cosmetology, 4: 41-55, 2014.

Choi BY, Kim JD. A study on perceptions and use of sheet type facial mask. Korean Society of Cosmetics and Cosmetology, 6: 163-177, 2016.

Hong SK, Kim MK. Female college students' interests in make-up according to recognition types of them. Journal of Digital Convergence, 13: 525-533, 2015.

Ha BJ, Kim JD, Yang HY, Choi EY, KO WB. Cosmetic chemistry. Soomoonsa, Seoul, p148, 2002.

Hong JI, Kim JD. Health state of women's skin and relevant life style. Journal of the Korean Society of Cosmetology, 13: 964-975, 2007.

Jang HS, O IY. A study on changes in skin texture expression according to make-up trend by the times. The Journal of the Korean Society of Make-up Design, 4: 237-248, 2008.

Jeong MA ,Mo JH, Kim HS. Components of preferred brands of anti-aging and anti-wrinkle cosmetics and satisfaction: centering on skin care cosmetics. Journal of the Korean Society of Design Culture, 17: 561-573, 2011.

Kim Jl. A research on perception of the cleansing by age. Asian Journal of Beauty and Cosmetology, 12: 15-25, 2007.

Kim JD, Kim EJ. A study on use of makeup cosmetics and the purchase behavior among female college students. The Journal of the Korean Society of Knit Design, 11: 1-14, 2013.

Kim JD. Study on female college students' recognition and state on skin care. The Journal of the Korean Society of Knit Design, 15: 54-65, 2017.

Kim T. Purchasing and using behavior according to the experiences of side effects. The Research Journal of the Costume Culture, 27: 169-180. 2019.

Kwon HJ. Beauty experts' perception awareness of Korean mask packs. Journal of the Korea Convergence Society, 10: 243-248, 2019.

Lim SS, Kwak SS, Kim AK. A study on skin conditions by water-soluble cleansers. Asian Journal of Beauty and Cosmetology, 8: 73-86, 2010.

Lee EY, Bae MK, An SS, Moon SJ, Chang IS, Koh HJ. A study on frequency and appearance of adverse effect according to type of cosmetics and in young adult Koreans. Asian Journal of Beauty and Cosmetology, 2: 131-140, 2004.

Lee EJ, Yim MH, Ku HY, Shin EK, Ann MJ, Whang WK. The actual condition of makeup and attitude on cleansing of teenage girls. Asian Journal of Beauty and Cosmetology, 7: 327-337, 2009.

Park SM. The study of cosmetics purchasing behavior act 
according to the transtheoretical model of the female university students. Asian Journal of Beauty and Cosmetology, 11: 351-359, 2013.

Shin EJ, Jeon MJ, Sakong J . Knowledge, attitude and practice on skin health care of high school girls. Journal of the Korean Society of Cosmetology, 15: 200-212, 2009.

Song JH , Kim BJ, Choi EJ. The actual status of face washing in women in their 20s and 30s and the influence of cleansing oil upon the improvement of their facial skin dryness. Asian Journal of Beauty and Cosmetology, 8 : 11-20, 2010.

Vie K, Pons-Guiraud A, Dupuy P, Maibach H. Tolerance profile of a sterile moisturizer and moisturizing cleanser in irritated and sensitive skin. American Journal of Contact Dermatitis, 11: 61-164, 2000. 


\section{국문초록}

\section{0대 여대생의 화장품 사용과 피부관리를 위한 행동방안 연구}

도은정 ${ }^{1}$ 황해정 ${ }^{2 *}$

${ }^{1}$ 예랑 아트 스쿨, 서울, 한국

${ }^{2}$ 이누리 평생교육원, 서울, 한국

목적: 최근 낮아지는 메이크업 연령층의 잘못된 지식 습득과 습관의 오류를 바로잡고 화장 교육의 필요성을 위한 기초자료가 되고 자 20대 젊은 연령층의 피부관리를 위한 화장품 사용 및 피부관리 행동 방안를 조사하는 연구를 실시하였다. 방법: 서울/경기 소재 대학교 20 대 여대생 130 명을 대상으로 설문 조사하여 일반적 특성, 피부 관리 지식 및 행위는 빈도분석(frequency analysis) 하였고 화장품 부작용 경험에 대한 인자의 독립성 검증은 카이제곱 검정 통계량으로 분석하였다, 연구의 통계 처리는 SPSS WIN 12.0 프 로그램으로 분석하였다. 결과: 20 대 여성들은 결점 커버를 위해서 색조화장품 중 베이스(파운데이션)을 가장 많이 사용하였고 세안 시 미지근한 물을 사용해야 한다는 인식이 높았다. 세안 시 전문세안제를 사용한 후 피부가 예전보다 좋아졌고, 경제적 부담을 이유 로 스스로 피부관리 하였고, 자가관리법으로 마사지와 팩을 많이 사용하고 그 효과를 신뢰하였다. 화장품 부작용 경험에 영향을 주 는 인자는 화장품 도구의 세척 여부( $p$-value 0.022), 피부관리 여부( $p$-value 0.005) 인 것으로 나타났다. 결론: 본 연구를 통해서 점점 낮아지고 있는 화장 연령층이 화장품에 대한 정보 오류와 잘못된 화장품 사용 및 생활 습관으로 피부 부작용을 경험하지 않도 록 하는 기초 자료로 활용되고, 화장품에 대한 정보 공개의 다양성과 교육의 기회가 제공되어지는 계기가 되길 바란다.

핵심어: 베이스(파운데이션), 세안, 전문세안제, 마사지, 팩

\section{참고문헌}

권혜진. 한국 마스크팩에 대한 미용종사자들의 인식 조사. 한국융합학회논문지, 10: 243-248, 2019.

김종임. 세안(클렌징)에 대한 연령별 인지도 조사연구. 아시안뷰티화장품학술지, 12: 15-25, 2007.

김주덕, 김은지. 여대생들의 메이크업 화장품에 대한 사용실태 및 구매행동에 관한 연구. 패션과 니트, 11: 1-14, 2013. 김주덕. 여대생들의 피부관리 인식 및 실태에 관한 연구. 패션과 니트, 15: 54-65, 2017.

김태미. 화장품 부작용 경험과 구매 및 사용 행동 특성. 복식문화연구, 27: 169-180, 2019.

박선민. 여대생의 화장품 구매행동에 대한 범 이론적 모델을 적용한 비교 연구. 아시안뷰티화장품학술지, 11: 351-359, 2013.

백주현, 김주덕. 여성들의 세안에 대한 인식과 사용실태에 관한 연구. 한국화장품미용학회지, $4: 41-55,2014$.

신은정, 전만중, 사공준. 여고생들의 피부건강관리에 대한 지식, 태도 및 실천행위. 한국미용학회지, 15: 200-212, 2009.

송정희, 김봉조, 최은정. 20,30 대 여성들의 세안 실태와 클렌징 오일이 얼굴 피부건조 개선에 미치는 영향. 아시안뷰티화 장품학술지, 8: 11-20, 2010.

이은영, 배미옥, 안수성, 문성준, 장이섭, 고혜정. 한국 청년층의 화장품 유형별 부작용 빈도 및 증상에 대한 연구. 아시안 뷰티화장품학술지, 2: 131-140. 2004.

이은주, 임미현, 구희연, 신은경, 안미자, 황완균. 여중고생의 색조화장 실태 및 클렌징에 대한 태도. 아시안뷰티화장품학 술지, 7: 327-337, 2009.

임선형, 곽선순, 김애경. 세안화장품 사용에 따른 20 대 여대생의 피부상태 연구. 아시안뷰티화장품학술지, 8: 73-86, 2010.

장혜선, 오인영. 시대별 메이크업 트렌드에 따른 피부 질감표현 변화에 관한 연구: 태평양 화장품 1980 2008년까지 지면 
과고를 중심으로. 한국메이크업디자인학회지, 4: 237-248, 2008.

정명아, 모정희, 김한식. 노화 및 주름개선화장품 선호브랜드의 성분현황과 만족도: 피부관리 화장품을 중심으로. 한국디 자인문화학회지, 17: 561-573, 2011.

최보윤, 김주덕. 시트형 마스크 팩에 대한 인식 및 사용실태에 관한 연구. 한국화장품미용학회지 6: 163-177. 2016. 하병조, 김주덕, 양현옥, 최은영, 고원배. 화장품화학. 수문사, 서울, p148, 2002.

홍수경, 김민경. 여대생들의 메이크업 인식 유형에 따른 관심도. 디지털융복합연구, 13: 525-533. 2015.

홍진이, 김주덕. 여성의 피부건강상태 및 관련 생활행태의 연구. 한국미용학회지, 13: 964-975, 2007. 


\section{中文摘要}

\section{0多岁女大学生使用化妆品和护肤品的行为研究}

都垠廷 ${ }^{1}$, 黄海貞 $^{2+}$

${ }^{1}$ Ye-rang艺术学校, 首尔, 韩国

${ }^{2} e-N u r i$ 终身教育院，首尔，韩国

目的: 为了纠正对年轻人群使用化妆的误解并提供受教育的机会, 本研究分析了20岁以下年轻人的化妆使用和 皮肤护理行为。方法: 对首尔/京畿道的130名女学生进行了有关一般特征, 皮肤知识和行为的调查。使用SPSS WIN 12.0软件对调查数据进行频率分析以进行统计处理。结果: 大多数接受调查的20多岁女性使用底妆（粉底 妆）遮盖瑕疵, 并且人们广泛认识到洗脸时应使用温水。使用专业的洗面奶可改善面部皮肤外观。但是, 由于 经济负担, 大多数参与者通常使用自我管理的皮肤护理。面部按摩和包装是广泛使用的自我护理治疗方法, 大 多数受访者认为这些治疗方法是有效的。化妆品产生副作用的最常见原因包括清洁化妆品工具 $(p=0.022)$ 和皮 肤护理方法 $(p=0.005)$ 。结论: 本研究为年轻的化妆品使用者提供指导, 以克服与化妆品有关的错误信息, 错 误使用和不良习惯。本文还为各种化妆品提供了信息, 通过应用信息, 学生在使用化妆品时可能会降低皮肤不 适的发生率。

关键词：基础（粉底），洗脸，专业清洁剂，消息，包装 
